\title{
A linguagem (re)descoberta: contornos prospectivos da leitura barthesiana de Benveniste
}

\author{
Carolina Knack ${ }^{1}$ \\ Instituto de Letras, Universidade Federal do Rio Grande do Sul, Porto Alegre, RS, Brasil
}

Resumo: Este estudo tem o propósito de abordar efeitos da leitura barthesiana de Benveniste. Para tanto, primeiramente, empreende-se uma "leitura transversal" (ROSÁRIO, 2018) de "Por que gosto de Benveniste" (BARTHES, 2012a), texto do qual se recupera o apontamento relativo às contribuições benvenistianas para o cenário da linguística a partir da centralidade da categoria de pessoa. Como essa categoria, segundo Barthes, interessaria também à literatura, empreende-se, em seguida, uma "leitura vertical" (ROSÁRIO, 2018) do ensaio "Escrever, verbo intransitivo?" (BARTHES, 2012b), texto a partir do qual Barthes discute não só a categoria de pessoa, mas também a de temporalidade e a de diátese, as três profundamente abordadas por Benveniste. Tais categorias são deslocadas por Barthes para o campo literário, a fim de teorizar a respeito da atividade de escritura, movimento que evidencia efeitos das reflexões benvenistianas sobre as barthesianas.

Palavras-chave: Linguística da Enunciação; Literatura; Teoria da Escritura.

Title: Language (re)discovered: prospective outlines of Benveniste's Barthesian reading

Abstract: This study aims to approach Benveniste's Barthesian reading effects. In this regard, it is performed, at first, a "transversal reading" (ROSÁRIO, 2018) of "Why I Love Benveniste" (BARTHES, 2012a), a text that retrieves a note related to the Benvenistian contributions to the linguistics scenario from the centrality of the category of person. As this category, according to Barthes, would also interest literature, this paper makes, thereafter, a "vertical reading" (ROSÁRIO, 2018) of "To Write: An Intransitive Verb" (BARTHES, 2012b), an essay that Barthes does not only discuss the category of person, but also of temporality and of diathesis, all of them deeply approached by Benveniste, which are dislocated by Barthes to the literary field, in order to theorize about the activity of writing, a movement that reveals effects of the Benvenistian reflections on the Barthesian ideas.

Keywords: Linguistics of Enunciation; Literature; Theory of Writing.

\footnotetext{
${ }^{1}$ Doutora em Estudos da Linguagem pelo Programa de Pós-Graduação em Letras da Universidade Federal do Rio Grande do Sul (UFRGS). Professora Adjunta do Departamento de Letras Clássicas e Vernáculas do Instituto de Letras da Universidade Federal do Rio Grande do Sul (UFRGS). Orcid: https://orcid.org/0000-0001-84997087. E-mail: carolinaknack@gmail.com
} 
Nunca lhe aconteceu, ao ler um livro, interromper com frequência a leitura, não por desinteresse, mas, ao contrário, por afluxo de ideias, excitações, associações? Numa palavra, nunca lhe aconteceu ler levantando a cabeça?

É essa leitura, ao mesmo tempo irrespeitosa, pois que corta o texto, e apaixonada, pois que a ele volta e dele se nutre, que tentei escrever.

Roland Barthes Escrever a leitura

\section{Palavras iniciais}

Barthes, no trecho que escolho como epígrafe deste texto, revela sua excitação ao ler Sarrasine, de Balzac ${ }^{2}$. Se me aproprio de seu testemunho, é porque, de minha parte, eu (re)li Barthes levantando a cabeça. A cada levantar, uma pausa para apreciar a sua escritura, por vezes enigmática, quase cifrada; por vezes tão direta, quase clara. Nesse processo de interrogar a minha própria leitura e "sistematizar todos esses momentos em que a gente 'levanta a cabeça'” (BARTHES, 2012d, p. 26), nasceu este texto, um texto-leitura, para usar uma expressão barthesiana, o qual foi apresentado no Terceiro Colóquio Leituras de Émile Benveniste, realizado na Universidade Federal de Pelotas (UFPel), em 10 e 11 de outubro de 2019, na cidade de Pelotas (RS).

Inspirada na proposta do Colóquio, neste trabalho busco explorar alguns "Efeitos da teoria da linguagem de Benveniste na composição da reflexão de campos conexos aos estudos da linguagem", neste caso, na composição de reflexões produzidas por Roland Barthes, admirador confesso de Benveniste: "Lemos outros linguistas (afinal, é preciso), mas gostamos de Benveniste", confidencia Barthes (2012a, p. 213).

Barthes é um autor tão plural quanto Benveniste ${ }^{3}$. Não seria absurdo estender àquele a noção de universo que Teixeira e Messa (2015) atribuem a este: se o universo benvenistiano evidencia a multiplicidade de interesses desse autor, os quais abarcam desde problemáticas ligadas aos estudos comparatistas até as relativas aos estudos enunciativos, semiológicos e literários, é possível também pensar em um universo barthesiano, dado o interesse de Barthes por problemáticas que abarcam desde a crítica, a teoria e a escrita literária até a teorização e a análise semiológica, englobando objetos como os mitos, a moda e a fotografia.

Em prefácio à obra O rumor da língua (BARTHES, 2012), Perrone-Moisés destaca que os grandes temas barthesianos envolvem linguagem e literatura, sendo estes os que

\footnotetext{
${ }^{2}$ Obra que, inclusive, foi seu objeto de análise ao longo de um seminário de dois anos (1968-1969) na École Pratique des Hautes Études e que configurou, posteriormente, sua obra S/Z (BARTHES, 1970).

${ }^{3}$ A obra Roland Barthes Plural, organizada por Claudia Amigo Pino, Laura Tadei Brandini e Márcio Venício Barbosa (SP: Editora Humanitas, 2017) dá uma amostra dos múltiplos interesses de Barthes, revisitados por pesquisadores brasileiros e estrangeiros. De modo transversal aos textos que compõem a coletânea, há a presença da noção de "plural", termo empregado por Barthes em diversos escritos, tal como explicam os organizadores em introdução à obra.
} 
comparecem na maioria dos ensaios que compõem a obra em questão. De acordo com a autora, é possível considerar, para fins didáticos, a existência de quatro etapas na vida intelectual de Barthes, a saber, "o mitólogo, o 'novo-crítico', o semiólogo e o escritor" (PERRONE-MOISÉS, 2012, p. XII), sendo as "duas últimas fases ou faces" as que se presentificam nos ensaios de $O$ rumor da língua. No que se refere a essas "fases ou faces", a autora salienta a existência de deslocamentos progressivos operados por Barthes, os quais vão dando, pouco a pouco, forma a suas propostas.

Diante dessa pluralidade e ciente das transformações pelas quais a teorização barthesiana passa ao longo dos anos, formulo, a partir da proposta do Terceiro Colóquio Leituras de Émile Benveniste, uma questão geral que organiza o percurso deste trabalho: que efeitos têm as reflexões de Émile Benveniste sobre as reflexões de Roland Barthes?

Para dar especificidade a essa ampla questão geral, escolhi partir de um texto conhecido dos benvenistianos: trata-se de Por que gosto de Benveniste, que reúne as duas resenhas de Barthes acerca de Problemas de Linguística Geral I (PLG I) e Problemas de Linguística Geral II (PLG II), obras de autoria de Émile Benveniste. As resenhas foram publicadas, respectivamente, em 1966 e 1974, ambas em La Quinzaine Littéraire, e reunidas, posteriormente, em $O$ rumor da língua (BARTHES, 2012). Valho-me apenas da primeira resenha, que considero, empregando os termos de Rosário (2018), um "texto de contextualização" do qual faço uma "leitura transversal"4. Isso significa que não esmiúço tal texto, apenas dele recupero alguns pontos que me conduziram à proposição de uma questão específica de pesquisa.

Barthes (2012a, p. 207), na abertura da primeira resenha, afirma que nosso tempo seria marcado por grandes explorações, dentre as quais aquela relativa à linguagem: "temos de descobrir a linguagem", afirma ele. Eu diria que Barthes (re)descobre a linguagem lendo, dentre outros linguistas necessários, Benveniste. Os elogios tecidos ao linguista são vários ao longo da resenha e salientam desde o seu rigor até o caráter prospectivo de suas pesquisas ${ }^{5}$.

Descrevendo a organização de Problemas de Linguística Geral I, Barthes destaca, primeiro, os textos que tratam do panorama da linguística atual, certamente a Primeira Parte de PLG I, intitulada Transformações da Linguística. Depois, situa o restante da obra em torno de "pontos cardeais do espaço linguístico", pontos traduzidos em quatro termos - a comunicação, a estrutura, a significação e a pessoa -, conforme se vê no parágrafo em questão reproduzido a seguir. O autor salienta ser esta última, a pessoa, "parte decisiva da

\footnotetext{
${ }^{4}$ Rosário (2018), em sua tese de doutorado, cunha a terminologia "textos de contextualização", "textos de teorização" e "textos de divulgação" para a abordagem dos textos benvenistianos. A consideração de um texto em uma ou outra dessas categorias dependerá da questão de pesquisa proposta pelo leitor-pesquisador, assim como dela dependerá a mobilização de cada texto em termos de método de leitura: quando objeto de uma discussão detalhada, trata-se de uma "leitura vertical" (ROSÁRIO, 2018, p. 60); quando objeto de "uma leitura que os atravessa apenas em certos pontos", trata-se de uma "leitura transversal” (ROSÁRIO, 2018, p. 60).

${ }^{5} \mathrm{~A}$ título de exemplo do tom elogioso de Barthes, veja-se o seguinte apontamento: "Benveniste tem a coragem de colocar deliberadamente a linguística no ponto de partida de um movimento muito vasto e de já adivinhar o desenvolvimento futuro de uma verdadeira ciência da cultura, na medida em que a cultura é essencialmente linguagem" (BARTHES, 2012a, p. 209).
} 
obra, onde Benveniste analisa essencialmente a organização dos pronomes e dos tempos" (BARTHES, 2012a, p. 208).

Os primeiros textos tratam de uma descrição da linguística atual: recomendamos aqui o belíssimo artigo que Benveniste consagra a Saussure [...]. Os artigos que vem a seguir ocupam os pontos cardeais do espaço linguístico: a comunicação, ou ainda o signo articulado, situado em relação ao pensamento, à linguagem animal e à linguagem onírica; a estrutura (evoquei [anteriormente] o texto capital sobre os níveis da análise linguística: é preciso ainda assinalar o texto, fascinante de clareza, em que Benveniste estabelece o sistema sublógico das preposições em latim; por que não nos explicaram isso quando fazíamos versões latinas: tudo se esclarece pela estrutura; a significação (pois é sempre do ponto de vista do sentido que Benveniste interroga a linguagem); a pessoa, a meu ver parte decisiva da obra, onde Benveniste analisa essencialmente a organização dos pronomes e dos tempos. A obra termina com alguns estudos do léxico. (BARTHES, 2012a, p. 208, grifo itálico do autor, grifo negrito nosso).

Com a releitura desse texto, passei a me interrogar: de que modo Barthes via essa importância capital da categoria de pessoa? Indicativos para uma interpretação são apresentados no próprio texto, alguns parágrafos adiante.

Barthes (2012a, p. 209) chama a atenção para três contribuições que ele julga das mais importantes relativas à obra de Benveniste: i) a voz média dos verbos indo-europeus, ii) a estrutura dos pronomes pessoais e iii) o sistema dos tempos em francês. $O$ autor enfatiza que essas três contribuições tratam diversamente da noção de pessoa, categoria que vincula sujeito e instância de discurso, conforme se lê no parágrafo a seguir.

\footnotetext{
Vejam três contribuições das mais importantes: uma sobre a voz média dos verbos indo-europeus, a segunda sobre a estrutura dos pronomes pessoais, a terceira sobre o sistema dos tempos em francês; as três tratam diversamente de uma noção capital em psicologia: a de pessoa. Ora, Benveniste consegue, magistralmente, arraigar essa noção numa descrição puramente linguística. De modo geral, ao colocar o sujeito (no sentido filosófico do termo) no centro das grandes categorias de linguagem, ao mostrar, ao ensejo de fatos muito diversos, que o sujeito jamais pode distinguir-se de uma "instância de discurso", diferente da instância da realidade, Benveniste fundamenta linguisticamente, quer dizer, cientificamente, a identidade do sujeito e da linguagem, posição que está no cerne de muitas pesquisas atuais e que interessa tanto à filosofia quanto à literatura; tais análises indicam, talvez, a saída para uma velha antinomia, mal liquidada: a do subjetivo com o objetivo, do indivíduo com a sociedade, da ciência com o discurso. (BARTHES, 2012a, p. 209-210, grifo itálico do autor, grifo negrito nosso).
}

A relevância dessa ênfase nas contribuições atreladas à categoria de pessoa em associação com outras, para além da própria pertinência para a linguística, parece residir, segundo Barthes, no interesse atual que essa posição pode ter tanto à filosofia quanto à literatura.

Nesse ponto, lembrando a epígrafe deste trabalho, "levanto a cabeça" e me pergunto, considerando, agora, o laço de Barthes com o campo literário: como essa posição interessa à literatura? 
A partir dessa resenha, considerada "texto de contextualização" (ROSÁRIO, 2018), passei a percorrer outros textos do autor em busca de vestígios que pudessem auxiliar a compreender se esse interesse se convertia em traços teóricos nas entrelinhas da escrita barthesiana. Tal percurso me conduziu ao ensaio Escrever, verbo intransitivo?, texto apresentado por Barthes no Colóquio Johns Hopkins, em 1966, posteriormente publicado, em 1970, em inglês, em The Languages of Criticism and the Sciences of Man: the Structuralist Controversy e, depois, inserido na coletânea O rumor da língua (BARTHES, 2012).

Em meu entendimento, esse ensaio permite evidenciar alguns efeitos das reflexões benvenistianas sobre as barthesianas - minha questão geral -, na medida em que o objetivo de Barthes em tal texto consiste em mostrar "como a atividade de escritura pode ser hoje enunciada com a ajuda de certas categorias linguísticas" (BARTHES, 2012b, p. 14), proposta que desenha a partir da retomada e do deslocamento de proposições benvenistianas. Eis, portanto, a questão específica que derivo deste texto: que categorias linguísticas são essas que permitem a Barthes pensar os contornos de sua noção de escritura?

Recorrendo novamente à terminologia de Rosário (2018), considero o referido ensaio um "texto de teorização", do qual faço, portanto, uma "leitura vertical", que explora minuciosamente seu funcionamento. Em termos metodológicos, cabe destacar que me restrinjo a examinar, neste trabalho, apenas tal ensaio que, junto da primeira resenha, configuram meu corpus textual de pesquisa. Essa expressão foi cunhada por Flores (2013, p. 21) no âmbito dos estudos da obra de Émile Benveniste, uma vez que, diante da sua amplitude, é preciso esclarecer qual parte de sua obra está sob enfoque: "Do conjunto da obra - entendido como um corpus inicial formado por fontes de diferentes naturezas recorta-se, com base em objetivos específicos, um corpus textual de pesquisa" (FLORES, 2013, p. 21, grifo do autor). Entendo que essa mesma posição deve ser tomada frente à obra barthesiana, motivo pelo qual sistematizo, no quadro a seguir, minhas opções metodológicas.

Quadro 1 - Corpus textual de pesquisa

\begin{tabular}{|c|c|}
\hline \multicolumn{2}{|c|}{ Corpus textual de pesquisa (FLORES, 2013) } \\
\hline $\begin{array}{c}\text { Texto de contextualização } \rightarrow \text { Leitura transversal } \\
\text { (ROSÁRIO, 2018) }\end{array}$ & $\begin{array}{c}\text { Por que gosto de Benveniste (BARTHES, 2012a) } \\
\text { (Parte V de O rumor da língua) }\end{array}$ \\
\hline $\begin{array}{c}\text { Texto de teorização } \rightarrow \text { Leitura vertical } \\
\text { (ROSÁRIO, 2018) }\end{array}$ & $\begin{array}{c}\text { Escrever, verbo intransitivo? (BARTHES, 2012b) } \\
\text { (Parte I de O rumor da língua) }\end{array}$ \\
\hline
\end{tabular}

Fonte: elaborado pela autora.

Assim, na seção a seguir, detenho-me a examinar o ensaio Escrever, verbo intransitivo? (BARTHES, 2012a). Por fim, na última seção, esboço algumas respostas para as questões geral - que efeitos têm as reflexões de Émile Benveniste sobre as reflexões de Roland Barthes? - e específica - que categorias linguísticas permitem a Barthes pensar os contornos de sua noção de escritura? - que deram forma a este trabalho, de modo a delinear alguns contornos prospectivos da leitura barthesiana de Benveniste. 


\section{Da linguística à literatura: possíveis efeitos das reflexões de Benveniste nas proposições de Barthes em Escrever, verbo intransitivo?}

No ensaio Escrever, verbo intransitivo?, Barthes, segundo suas próprias palavras, tem por objetivo indicar, "por algumas observações breves, prospectivas e não conclusivas, como a atividade de escritura pode ser hoje enunciada com a ajuda de certas categorias linguísticas" (BARTHES, 2012b, p. 14).

A noção de escritura vinha sendo desenhada pelo autor desde os anos 50, com a publicação de $O$ grau zero da escrita (1953, em francês: Le degré zero de l'écriture). Não é meu propósito recuperar os meandros e a historicidade da configuração de sua noção da escritura $^{6}$. Ainda assim, é preciso pontuar que, na obra 0 grau zero da escrita, Barthes (2004), problematizando a literatura, deflagra seu permanente interesse nos laços entre o escritor e sua escritura. O olhar de Barthes para o texto literário e para a figura do escritor está calcado na linguagem. É disso que ele está a falar em $O$ grau zero: a escritura implica uma problemática da linguagem e da sociedade (BARTHES, 2004, p. 66). Porém, nessa obra, segundo Bellocchio (2016), Barthes ainda trata de modo disperso desses aspectos.

Considerando esse cenário, retorno ao propósito que Barthes delineia na abertura de Escrever, verbo intransitivo? - "como a atividade de escritura pode ser hoje enunciada com a ajuda de certas categorias linguísticas" (BARTHES, 2012b, p. 14) - e me restrinjo, tal como já sinalizado, a responder à seguinte questão específica: que categorias linguísticas são essas que permitem ao autor pensar, mais de dez anos após O grau zero, os contornos de sua noção de escritura? Dentre essas categorias, hipotetizo estar a de pessoa, uma vez que, em Por que gosto de Benveniste, Barthes (2012a) dá ênfase a essa decisiva contribuição do linguista e destaca a posição do sujeito na linguagem como ponto de interesse para o campo literário.

Examinando globalmente o ensaio, o primeiro aspecto que chama a atenção é a divisão do texto em seções e os títulos dados a essas seções: 1. Literatura e linguística; 2. A linguagem; 3. A temporalidade; 4. A pessoa; 5. A diátese; 6. A instância do discurso.

Facilmente se constata que as seções 3,4 e 5 recebem títulos que remetem às "contribuições benvenistianas" enfatizadas por Barthes na resenha. Já se pode, assim, supor as categorias de que o autor se valerá. Antes de passar a elas, e considerando o encadeamento de seu raciocínio no texto, passo a destacar, sinteticamente, aspectos que julgo como "ecos" da voz de Benveniste nas proposições de Barthes nas seções 1 e 2 do ensaio.

Na primeira seção, Literatura e linguística, Barthes (2012b, p. 14) afirma que "a literatura e a linguagem estão se reencontrando" e que, dentre os muitos fatores dessa aproximação, está “o desenvolvimento da própria linguística, que doravante inclui no seu

\footnotetext{
${ }^{6}$ Escritura é termo que, segundo Perrone-Moisés (2013), mais bem define a proposição de Barthes.
} 
campo o poético"7. Trata-se, segundo Barthes, da existência de uma perspectiva nova de reflexão, que é comum a ambas, à literatura e à linguística, no que diz respeito ao escritor, e que geraria uma "uma crítica de linguagem" (BARTHES, 2012b, p. 14). O teórico afirma situar-se nessa perspectiva para explorar a atividade de escritura a partir de categorias linguísticas.

O autor passa, então, à segunda seção do texto, em que aborda a Linguagem. Considerando a escritura como um sistema de signos, ele propõe uma perspectiva que trataria das relações entre o escritor e a língua, denominada semiocrítica por ele, o que o leva a sintetizar aspectos da "antropologia linguística", para ele a "linguística atual" (BARTHES, 2012b, p. 15). Tais aspectos, considerados "'verdades', ainda que provisórias", em suas palavras, têm "força de provocação", motivo pelo qual as resume em itens, numerados de 1 a 4 no texto. Em cada um deles, percebo ressoar a voz de Benveniste, o que denuncia, a meu ver, possíveis efeitos das reflexões benvenistianas nas proposições barthesianas, conforme buscarei demonstrar.

No primeiro item, por exemplo, Barthes explica que a busca por visualizar na escritura categorias fundamentais da linguagem evidencia que a linguagem é para o escritor a origem, e não o contrário. Esse aspecto liga-se, de certo modo, ao segundo item formulado pelo autor:

2) Um segundo princípio, particularmente importante no que diz respeito à literatura, é que a linguagem não pode ser considerada um simples instrumento, utilitário ou decorativo, do pensamento. O homem não preexiste à linguagem [...]. Jamais atingimos um estado em que o homem estivesse separado da linguagem, que elaboraria então para "exprimir" o que nele se passasse: é a linguagem que ensina a definição do homem, não o contrário. (BARTHES, 2012b, p. 15).

São evidentes, nesse trecho, os ecos do artigo Da subjetividade na linguagem (BENVENISTE, 2005c) ${ }^{8}$, no qual Benveniste define que "Não atingimos nunca o homem separado da linguagem e não o vemos nunca inventando-a" e que "É um homem falando que encontramos no mundo, um homem falando com outro homem, e a linguagem ensina a própria definição de homem" (BENVENISTE, 2005c, p. 285).

Também no terceiro item elencado por Barthes é possível perceber ecos benvenistianos. Nesse item, sob um viés metodológico, o autor explica que

\footnotetext{
${ }^{7}$ Nesse ponto inicial do ensaio, é evidente a conexão com a reflexão de Roman Jakobson, especialmente a proposta em Linguística e Poética, texto publicado originalmente em 1960, em Style in Language (obra organizada por Thomas Sebeok), e, depois, junto à obra Linguística e Comunicação (Cf. Jakobson). Como o propósito de meu estudo consiste em visualizar possíveis efeitos das proposições de Benveniste nas formulações de Barthes, não destacarei, daqui por diante, aspectos que possam remeter a outros autores, como Jakobson, por exemplo.

${ }^{8} \mathrm{O}$ artigo Da subjetividade na linguagem foi originalmente publicado por Benveniste em 1958, no Journal de psychologie. O texto integra a quinta parte de Problemas de Linguística Geral I (BENVENISTE, 2005), parte nomeada por Benveniste de $O$ homem na língua.
} 
A linguística, por um lado, sugere-nos distinguir níveis de análise e descrever os elementos distintivos de cada um desses níveis, em suma, fundamentar a distinção do fato e não o próprio fato; e, por outro lado, convida-nos a reconhecer que, contrariamente aos fatos físicos e biológicos, os fatos de cultura são dúplices, remetem a alguma outra coisa: como observou Benveniste, é a descoberta da "duplicidade da linguagem" que faz todo o valor da reflexão de Saussure. (BARTHES, 2012b, p. 15-16)

Esse trecho evoca, primeiramente, as considerações do artigo Os níveis da análise linguística (BENVENISTE, 2005e), texto em que Benveniste (2005e, p. 127) pensa a respeito do "fato linguístico" e do "que se deve admitir como fato, isto é, aos critérios que o definem como tal", delimitando a pertinência de procedimentos de análise para os quais a noção de nível é essencial. O linguista descreve, à luz da relação forma - sentido, as unidades que configuram cada nível (fonemático, morfemático, categoremático), constatando que é o sentido "a condição fundamental" para as unidades constituírem-se como tais. Em linhas gerais, é isso que Barthes recupera, conforme o início do trecho citado.

Já ao final do trecho, Barthes faz referência a Benveniste, embora não ao texto específico do qual a informação provém, a saber, o artigo Saussure após meio século (BENVENISTE, 2005f) ${ }^{9}$. Neste, Benveniste (2005e, p. 47) afirma que "se deveria estabelecer uma distinção fundamental entre duas ordens de fenômenos: de um lado os dados físicos e biológicos" e "de outro lado, os fenômenos próprios ao meio interumano", fenômenos que, segundo aponta Benveniste (2005f, p. 47), "devem sempre ser recebidos como duplos, pelo fato de que se ligam a outra coisa". E conclui: "Um fato de cultura não o é a não ser na medida em que remete a algo diferente" (BENVENISTE, 2005f, p. 47). Barthes sintetiza esses aspectos, inclusive remetendo a Benveniste.

Por fim, Barthes apresenta um quarto item, que reúne os demais, na medida em que considera a cultura como um sistema de símbolos e prevê "a constituição de uma ciência única da cultura, que se apoiará, por certo, em disciplinas diversas" (BARTHES, 2012b, p. 16). A semiocrítica aludida pelo autor será, segundo ele, uma parte dessa ciência que, "seja como for, permanecerá sempre um discurso sobre a cultura" (BARTHES, 2012b, p. 16). Tal como nos segmentos textuais analisados anteriormente, neste também são visíveis ecos de reflexões de Benveniste, especialmente as de Vista d'olhos sobre o desenvolvimento da linguística (2005g, p. 32), texto em que o linguista discute a cultura como "um fenômeno inteiramente simbólico" e prospecta que "as ciências vizinhas" à linguística e as "pesquisas paralelas gerarão novas disciplinas e concorrerão para uma verdadeira ciência da cultura que fundará a teoria das atividades simbólicas do homem" (BENVENISTE, 2005g, p. 32).

$\mathrm{Na}$ continuidade do quarto item, Barthes, considerando o fato de que tal ciência se configura como "discurso sobre", formula um postulado que nomeia de "postulado de homologia": "a estrutura da frase, objeto da linguística, encontra-se homologicamente na

${ }_{9}$ O artigo Saussure após meio século foi originalmente publicado por Benveniste em 1963, no Cahiers Ferdinand de Saussure. O texto integra a primeira parte de Problemas de Linguística Geral I (BENVENISTE, 2005), parte nomeada por Benveniste de Transformações da linguística. 
estrutura das obras: o discurso não é tão-somente uma adição de frases; ele próprio é, e assim se pode dizer, uma grande frase" (BARTHES, 2012b, p. 16). Nesse trecho, é possível considerar ecos da complexa discussão sobre frase e discurso que comparecem no artigo Os níveis da análise linguística (BENVENISTE, 2005e), do qual apenas recupero, por ora, a definição de que "A frase, criação indefinida, variedade sem limite, é a própria vida da linguagem em ação" (BENVENISTE, 2005e, p. 139) e, por isso, a frase tem "sentido e referência", de modo que "É no discurso atualizado em frases que a língua se forma e se configura" (BENVENISTE, 2005e, p. 140).

Barthes, então, converte o postulado que formula no quarto item - o de que a estrutura da frase é encontrada, de modo análogo, na estrutura das obras - em uma "hipótese de trabalho" e afirma ser segundo essa hipótese que ele "gostaria de confrontar certas categorias da língua com a situação do escritor com relação à escritura" (BARTHES, 2012b, p. 16).

Quais categorias? Constato tratar-se de temporalidade, pessoa e diátese, as que dão título às seções 3, 4 e 5 de Escrever, verbo intransitivo?, e que são as mesmas categorias destacadas por Barthes (2012a) na resenha. Passemos a essas categorias.

Na seção 3, Barthes trata da temporalidade. O autor recupera a discussão sobre tempo proposta por Benveniste - seu nome é referido textualmente -, concordando com o fato de que "o tempo linguístico tem sempre como centro gerador o presente da enunciação" (BARTHES, 2012b, p. 47). Tal constatação o faz percorrer a reflexão sobre o tempo no "sistema do discurso" e no "sistema da história", recorrendo, embora não o cite nominalmente, ao artigo As relações de tempo no verbo francês (BENVENISTE, 2005d) ${ }^{10}$. A conclusão é a de que a relação do enunciador com a enunciação determina o sistema temporal do discurso.

Mas como isso se confronta com a situação do escritor com relação à escritura?

A literatura, conforme Barthes, enquanto se colocava sob a égide do referente, não percebia esses fatos de linguagem. Hoje, ou seja, após esse transitar pela reflexão benvenistiana - assim constato a partir dos indícios textuais -, "a literatura descobre no desdobrar-se do discurso [...] sutilezas fundamentais" (BARTHES, 2012b, p. 18), que, para Barthes, estão ligadas a: i) perceber algo contado no plano da história, com o aoristo ${ }^{11}$, como vinculado à não pessoa - discussão que remete, claramente, ao que diz Benveniste no artigo anteriormente referido; e ii) ensinar ao escritor atual que é preciso distinguir "o presente do locutor [...] do presente da locução, móvel como ela e em que se instaura uma coincidência

\footnotetext{
${ }^{10} \mathrm{O}$ artigo As relações de tempo no verbo francês foi originalmente publicado por Benveniste em 1959, no Bulletin de la Société de Linguistique. O texto integra a quinta parte - nomeada O homem na língua - de Problemas de Linguística Geral I (BENVENISTE, 2005).

${ }^{11}$ Benveniste, em As relações de tempo no verbo francês, busca mostrar que os tempos do verbo francês se distribuem em dois sistemas distintos e complementares, configurando o plano da história e o plano do discurso. De acordo com o linguista, no plano da história, o tempo fundamental é o aoristo (equivalente ao passé simple em francês), o qual se caracteriza por ser "o tempo do acontecimento fora da pessoa de um narrador" (BENVENISTE, 2005d, p. 267).
} 
absoluta do evento e da escritura" (BARTHES, 2012b, p. 18).

Em outros termos, Barthes desloca a reflexão sobre a temporalidade para seu objeto de interesse: a temporalidade na e da língua via enunciação é fundante para uma noção de escritura como atividade de linguagem.

$\mathrm{Na}$ seção 4, relativa à pessoa, Barthes sinaliza ser esta uma categoria universal, "ligada à antropologia da linguagem" e cita nominalmente Benveniste para explicar as correlações de pessoalidade e de subjetividade - correlações que o linguista explica em Estrutura das relações de pessoa no verbo ${ }^{12}$-, a partir das quais esmiúça eu e tu em oposição a ele, não pessoa. A partir disso, Barthes (2012b, p. 19) explica a "polaridade das pessoas", o que "não comporta nem igualdade nem simetria", havendo uma relação de "transcendência" de eu quanto a $t u$, sendo estes "inversíveis". Tal explicação retoma praticamente a mesma formulação de Da subjetividade na linguagem (BENVENISTE, 2005c, p. 286). Além disso, Barthes emprega uma citação direta de Benveniste, entre aspas, para apresentar definição linguística de eu: "eu nada mais é do que 'a pessoa que enuncia a presente instância de discurso a conter a instância linguística eu' (Benveniste)" (BARTHES, 2012b, p. 19, grifo do autor). Os leitores benvenistianos imediatamente identificam que tal definição provém do texto $A$ natureza dos pronomes (2005b, p. 278) ${ }^{13}$. É importante salientar a que noção de instância de discurso é muito cara a Barthes. Não por acaso, a seção 6 do ensaio sob análise tem como título tal expressão, como mais adiante discutirei.

Após longamente apresentar essas definições, Barthes (2012b, p. 19) afirma que, a partir delas, formulará "algumas sugestões para uma análise do discurso literário". Novamente, cabe ressaltar que não se trata simplesmente da presença de reflexões benvenistianas, mas essencialmente de efeitos por elas produzidos na e pela leitura de Barthes, que as desloca em direção à literatura.

A primeira sugestão é a de que, independentemente das marcas presentes, tal como acontece com a temporalidade, "o discurso da obra fica submetido a um duplo sistema, o da pessoa e o da não pessoa" (BARTHES, 2012b, p. 20).

A segunda é que a definição da primeira pessoa como determinada pela instância de discurso ajuda a compreender o esforço de escritores para buscar distinguir, na narrativa, a "pessoa psicológica" e o "autor da escritura", o que agiria contra um discurso de que a forma literária seria a "expressão de uma interioridade constituída atrás e fora da linguagem" (BARTHES, 2012b, p. 20).

Por fim, considerando a precisão da análise linguística, Barthes(2012b, p. 21) assinala que "o eu de quem escreve eu não é o mesmo que o eu que é lido por $t u$ ", de tal modo que

\footnotetext{
${ }^{12} \mathrm{O}$ artigo Estrutura das relações de pessoa no verbo foi originalmente publicado por Benveniste em 1946, no Bulletin de la Société de Linguistique. O texto integra a quinta parte - nomeada O homem na língua - de Problemas de Linguística Geral I (BENVENISTE, 2005).

${ }^{13} \mathrm{O}$ artigo A natureza dos pronomes foi originalmente publicado por Benveniste em 1956, em For Roman Jakobson. O texto integra a quinta parte - nomeada O homem na língua - de Problemas de Linguística Geral I (BENVENISTE, 2005).
} 
essa dissimetria começa a preocupar a literatura, "mostrando-Ihe que a intersubjetividade, ou, talvez melhor dizendo, a interlocução" se configura não pelo simples efeito do diálogo, "mas por uma descida profunda, paciente e muitas vezes desviada, no labirinto do sentido" (BARTHES, 2012b, p. 21).

$\mathrm{Na}$ próxima seção de Escrever, verbo intransitivo?, a seção 5, Barthes aborda a diátese, que, segundo ele, pode "aclarar a atividade de escritura no seu centro, já que concerne ao próprio verbo escrever" (BARTHES, 2012b, p. 21, grifo do autor).

O verbo escrever já esteve sob o foco de Barthes em outro ensaio, chamado Escritores e escreventes, publicado orginalmente em 1960. Nele, o autor já se perguntava a respeito dos sentidos e da intransitividade de tal verbo ${ }^{14}$, ideia que retorna no texto aqui analisado, no qual o autor manifesta ser interessante "saber em que momento as pessoas puseram-se a empregar o verbo escrever de maneira intransitiva, passando a ser o escritor não mais aquele que escreve alguma coisa, mas aquele que escreve, absolutamente: essa passagem é certamente o sinal de uma importante mudança de mentalidade" (BARTHES, 2012b, p. 21), ligada ao escrever moderno, segundo o autor.

Mas, agora, Barthes argumenta que não seria nessa ideia de intransitividade que se deveria buscar a definição do escrever moderno. Onde se apoiar, então? Segundo ele, na diátese.

Essa temática, a da diátese, é abordada profundamente por Benveniste em Ativo $e$ médio no verbo (BENVENISTE, 2005a) ${ }^{15}$. Ainda que não referencie tal artigo e apenas cite o nome de Benveniste, há indícios de que é a esse texto que Barthes recorre, dada a semelhança textual das definições que apresenta.

De fato, Barthes retoma de Benveniste a ideia de que "a diátese designa a maneira como o sujeito do verbo é afetado pelo processo" (BARTHES, 2012b, p. 22) ${ }^{16}$. Como, no indoeuropeu, segundo Benveniste, esse sistema é triplo (ativo, médio e passivo), o ativo não se opõe ao passivo, mas sim ao médio. $\mathrm{E}$ é o médio que interessa a Barthes.

O exemplo que Barthes apresenta é o do clássico "sacrificar" (ritualmente): "é ativo se é o sacerdote que sacrifica a vítima em meu lugar e por mim" (BARTHES, 2012b, p. 22). No ativo, então, "o processo realiza-se fora do sujeito [do sacerdote], pois, se é verdade que o sacerdote faz o sacrifício, não é afetado por ele"17. Já quando "eu mesmo [tomando o cutelo

\footnotetext{
${ }^{14}$ Em Escritores e Escreventes, Barthes (1970, p. 35) relacionava o verbo escrever a duas figuras: i) ao escritor: para ele, à época, aquele que realiza uma função; "para o escritor, [o da palavra literária] escrever é um verbo intransitivo" (1970, p. 33); e ii) ao escrevente: aquele que realiza uma atividade; "os escreventes, por sua vez, são homens 'transitivos'” (1970, p. 35), pois a palavra é, para estes, um meio para um fim, como explicar, ensinar.

15 O artigo Ativo e médio no verbo foi originalmente publicado por Benveniste em 1950, no Journal de psychologie. O texto integra a quarta parte - nomeada Funções sintáticas - de Problemas de Linguística Geral I (BENVENISTE, 2005).

${ }^{16}$ Em Ativo e médio no verbo (BENVENISTE, 2005a, p. 185): “a 'voz', que é a diátese fundamental do sujeito no verbo; denota uma certa atitude do sujeito relativamente ao processo".

${ }^{17}$ Em Ativo e médio no verbo, Benveniste (2005a, p. 185) toma o exemplo do "sacrifício" e do "sacerdote" do gramático hindu Panini, conforme o sânscrito.
} 
das mãos do sacerdote] faço o sacrifício por minha conta", está-se diante do médio: "ao agir, o sujeito afeta-se a si mesmo, permanece sempre no interior do processo" (BARTHES, 2012b, p. 22).

Tais são as definições, aparentemente, parafraseadas de Ativo e médio no verbo: "No ativo, os verbos denotam um processo que se efetua a partir do sujeito e fora dele. No médio, que é a diátese que se definirá por oposição, o verbo indica um processo do qual o sujeito é a sede; o sujeito está no interior do processo" (BENVENISTE, 2005a, p. 187). E mais: as oposições entre ativo e médio "voltam sempre definitivamente a situar as posições do sujeito em face do processo, segundo ele seja aí exterior ou interior, e a qualificá-lo enquanto agente, segundo ele efetue, no ativo, ou efetue afetando-se, no médio" (BENVENISTE, 2005a, p. 189).

Interessa, pois, a Barthes essa relação de efetuar algo e concomitantemente ser afetado por esse algo, por isso sua ênfase na voz média do indo-europeu na seção em que trata de diátese. Ele desloca essa noção para propor, então, a sua visada sobre o escrever:

\begin{abstract}
Assim definida, a voz média corresponde inteiramente ao escrever moderno: escrever é hoje fazer-se o centro do processo de palavra, é efetuar a escritura afetando-se a si próprio, é fazer coincidir a ação e o afeto, é deixar o escritor no interior da escritura, não a título de sujeito psicológico [...], mas a título de agente da ação. (BARTHES, 2012b, p. 22, grifo do autor).
\end{abstract}

E conclui: "no escrever médio, a distância entre o escritor e a linguagem diminui", pois "o sujeito constitui-se como imediatamente contemporâneo da escritura, efetuando-se e afetando-se por ela" (BARTHES, 2012b, p. 23).

Na última seção do texto, intitulada $A$ instância de discurso, Barthes realiza uma espécie de síntese de seu raciocínio. Ao contrário do que se poderia esperar, ela não explora a noção de instância de discurso. Possivelmente, porque a considera implicada nas demais categorias abordadas anteriormente, o que se comprova com a presença de tal termo nas seções já exploradas. Novamente, mas agora em tom de síntese, são os deslocamentos das categorias linguísticas para o campo da literatura que mobilizam Barthes. Conclui o autor que, "da mesma forma que a temporalidade, a pessoa e a diátese delimitam o campo posicional do sujeito, assim a literatura moderna busca instituir, através de experiências várias, uma posição nova do agente da escritura na própria escritura" (BARTHES, 2012b, p. 24).

E nesse sentido interessa não mais a "instância da realidade ou do referente", mas a instância de discurso, noção benvenistiana relativa a um ato de dizer pelo qual o locutor coloca a língua em uso, o que leva Barthes a constatar que "o campo do escritor é a própria escritura, não como 'forma' pura, como foi concebida por uma estética da arte pela arte, mas de modo muito mais radical como único espaço possível de quem escreve" (BARTHES, 2012b, p. 24).

Em outras palavras, o escritor constitui-se como tal na e pela instância de discurso, 
daí a escritura ser o seu único espaço. Por conseguinte, assumem relevo as categorias fundamentais da língua abordadas por Barthes (pessoa, tempo, voz) que, nos colocam, segundo destaca o autor, "no âmago de uma problemática da interlocução" (BARTHES, $2012 b$, p. 24). E isso produz efeitos no modo como ele concebe a escritura, na medida em que o discurso como "o exercício mesmo da fala" dá a ver a relação constitutiva do locutor com seu dizer. Segundo Barthes (2012b, p. 24), essa constatação é "um escândalo, e sobre esse escândalo é que devemos trabalhar hoje, linguística e literariamente: buscamos aprofundar o 'pacto da fala' que une o escritor e o outro, de maneira que cada momento do discurso seja, a uma só vez, absolutamente novo e absolutamente compreendido".

Esse exame detalhado do ensaio Escrever, verbo intransitivo? mostra, efetivamente, como certas categorias linguísticas, no caso, temporalidade, pessoa e diátese, podem contribuir para uma teorização sobre a atividade de escritura, propósito delineado por Barthes na abertura do ensaio.

A título de sistematização, organizo, no quadro a seguir, os principais conceitos que entendo ser mobilizados por Barthes (2012b, p. 16) para, segundo ele mesmo delimita, "confrontar certas categorias da língua com a situação do escritor com relação à escritura".

Quadro 2 - Confronto de categorias da/na língua com a situação do escritor com relação à escritura

\begin{tabular}{|c|c|c|}
\hline Categorias & $\mathrm{Da} /$ na língua & $\mathrm{Da} /$ na escritura \\
\hline Temporalidade & $\begin{array}{l}\text { - Tempo linguístico: o centro } \\
\text { gerador é o presente da } \\
\text { enunciação. } \\
\text { - Duplo sistema: plano do } \\
\text { discurso e plano da história. }\end{array}$ & $\begin{array}{l}\text { - O escritor deve perceber o plano } \\
\text { da história ligado à não pessoa. } \\
\text { - O escritor deve aprender a } \\
\text { distinguir o presente do locutor do } \\
\text { presente da locução, esta que } \\
\text { instaura a coincidência do evento } \\
\text { e da escritura. }\end{array}$ \\
\hline Pessoa & $\begin{array}{l}\text { - Correlação de pessoalidade (eu- } \\
\text { tu/ele) e de subjetividade (eu/tu). } \\
\text { - Eu interior ao enunciado. } \\
\text { - Reversibilidade eu-tu. } \\
\text { - Definição de eu na instância de } \\
\text { discurso (ID). }\end{array}$ & $\begin{array}{l}\text { - O discurso da obra fica } \\
\text { submetido a um duplo sistema: } \\
\text { pessoa e não pessoa. } \\
\text { - A definição de eu pela ID ajuda a } \\
\text { compreender o esforço dos } \\
\text { escritores em discernir pessoa } \\
\text { psicológica e autor da escritura no } \\
\text { plano da narrativa. } \\
\text { - O eu de quem escreve eu não é } \\
\text { o mesmo que o eu lido por tu. }\end{array}$ \\
\hline
\end{tabular}




\begin{tabular}{|c|c|c|}
\hline \multirow[t]{2}{*}{ Diátese } & $\begin{array}{l}\text { - Voz do verbo: designa a maneira } \\
\text { como o sujeito é afetado pelo } \\
\text { processo. } \\
\text { - Indo-europeu: } \\
\text { • ativo, médio e passivo; } \\
\text { - ativo opõe-se ao médio; } \\
\text { - ativo = o sujeito realiza o } \\
\text { processo fora dele (“o sujeito } \\
\text { efetua”); } \\
\text { - médio = o sujeito está no } \\
\text { interior do processo (“o } \\
\text { sujeito efetua afetando-se”). }\end{array}$ & $\begin{array}{l}\text { - A diátese média define o } \\
\text { escrever moderno, “aclarando” a } \\
\text { atividade de escritura no seu } \\
\text { centro. } \\
\text { - O sujeito constitui-se como } \\
\text { contemporâneo da escritura, } \\
\text { efetuando-se e afetando-se por } \\
\text { ela. } \\
\text { - Escrever é fazer-se centro do } \\
\text { processo. } \\
\text { - O escritor está no interior da } \\
\text { escritura. }\end{array}$ \\
\hline & $\begin{array}{l}\text { Delimitação do campo posicional } \\
\text { do sujeito na língua. }\end{array}$ & $\begin{array}{l}\text { Delimitação do campo posicional } \\
\text { do agente da escritura na própria } \\
\text { escritura. }\end{array}$ \\
\hline
\end{tabular}

Fonte: Elaborado pela autora.

Tal como se pode perceber, Barthes desloca conceitos atrelados às categorias da língua - temporalidade, pessoa e diátese, profundamente discutidas por Benveniste, tal como almejei evidenciar ao longo deste trabalho - para outro campo, o da literatura. Ao deslocar esses conceitos, Barthes os ressignifica, dando-lhes novos contornos, o que, de um lado, testemunha a potencialidade dos fundamentos benvenistianos e, de outro, a genialidade inventiva, mas modesta, de Barthes (2012b, p. 16): "Não escondo que esse cotejo não tem uma força demonstrativa e que seu valor permanece por enquanto essencialmente metafórico: entretanto, talvez, na ordem dos objetos que nos ocupa, a metáfora tenha, mais do que se supõe, uma existência metodológica e uma força heurística". Eis os caminhos abertos por Barthes.

\section{Encaminhamentos para algumas palavras (não tão) finais}

Neste trabalho, meu propósito foi tão somente partilhar meu "texto-leitura", "esse texto que escrevemos em nós quando lemos" (BARTHES, 2012d, p. 28), no espaço privilegiado de interlocução oportunizado pelo Terceiro Colóquio Leituras de Émile Benveniste. Em um Colóquio sobre leituras ou leitores de Benveniste, não poderíamos deixar de tratar de Barthes, esse pensador ímpar que contribuiu profundamente para a difusão dos trabalhos de Benveniste e cujos textos continuam a fascinar, evidenciando, sobretudo, a potencialidade das reflexões benvenistianas.

Direcionada pelos eixos de trabalho do Terceiro Colóquio Leituras de Émile Benveniste, formulei uma ampla questão geral, objetivando evidenciar alguns efeitos que as reflexões de Émile Benveniste produzem sobre as reflexões de Roland Barthes. Meu ponto de partida, como texto contextualizador (ROSÁRIO, 2018), foi a primeira resenha de Barthes por ocasião da publicação de $P L G$ I. A resenha me conduziu a investigar como interessariam, 
para a literatura, as categorias benvenistianas lá indicadas a partir da centralidade da noção de pessoa. A leitura vertical (ROSÁRIO, 2018) de Escrever, verbo intransitivo?, ensaio em que Barthes (2012b, p. 14) se propôs a mostrar "como a atividade de escritura pode ser hoje enunciada com a ajuda de certas categorias linguísticas", encaminhou-me para a formulação de uma questão específica: que categorias linguísticas são essas que permitem ao autor pensar os contornos de sua noção de escritura?

No contexto do ensaio lido, tais categorias são a temporalidade, a pessoa e a diátese, as "três contribuições das mais importantes" da obra benvenistiana, conforme Barthes assinala na resenha. Examinando essas categorias, no ensaio, Barthes as desloca para o contexto da literatura, propondo a escritura, de modo radical, como o único espaço possível de quem escreve, de tal modo que o escritor está situado no interior da escritura e, como sujeito, constitui-se contemporaneamente a ela, efetuando-se e afetando-se por ela. Portanto, das categorias da e na língua, Barthes passa às categorias da e na literatura, situando a relação do escritor com a escritura.

É evidente, nessa formulação, que as três categorias referidas (pessoa, tempo e diátese) convocam outras noções, conexas a elas, como a de instância de discurso, definida por Benveniste, em A natureza dos pronomes (2005b, p.277), como "os atos discretos e cada vez únicos pelos quais a língua é atualizada em palavra por um locutor". É, sem dúvida, essa definição que permite a Barthes transitar da "instância do referente" para a "instância da linguagem". Nesse trânsito, nas reflexões seguintes do autor, é a noção de enunciação que passa a assumir progressivo protagonismo. Não por acaso, a resenha de Barthes sobre o PLG I/ dá justamente destaque a esse conceito: "Benveniste deu corpo científico a uma noção que assumiu maior importância no trabalho de vanguarda: a enunciação." (BARTHES, 2012a, p. 211). Ainda, "O interesse direto do novo livro de Benveniste está nisto: é o livro da enunciação." (BARTHES, 2012a, p. 212).

Os impactos da noção de enunciação benvenistiana na noção de escritura barthesiana (e noções conexas, como de leitura, autoria, entre outras) podem ser visualizados em diferentes ensaios de Barthes. Para citar apenas mais um exemplo, refiro dois excertos do texto A morte do autor (2012c), no qual Barthes destaca que

[...] a linguística acaba de fornecer para a destruição do Autor um instrumento analítico precioso, mostrando que a enunciação em seu todo é um processo vazio que funciona perfeitamente sem que seja necessário preenchê-lo com a pessoa dos interlocutores: linguisticamente, o autor nunca é mais do que aquele que escreve, assim como "eu" outra coisa não é senão aquele que diz "eu": a linguagem conhece um "sujeito", não uma "pessoa", e esse sujeito, vazio fora da enunciação que o define, basta para "sustentar" a linguagem, isto é, para exauri-la. (BARTHES, 2012c, p. 60).

Destaca também o autor que "outro tempo não há senão o da enunciação, e todo texto é escrito eternamente aqui e agora" (BARTHES, 2012c, p. 61, grifo do autor).

Se Barthes, continuamente, formula e reformula sua teorização, como afirma 
Perrone-Moisés, penso poder afirmar que as leituras que ele fez dos textos benvenistianos, dentre outras de outros tantos autores, também contribuem para essas (re)formulações. Nesse sentido, retomando o título de minha fala, eu diria que Barthes (re)descobre a linguagem lendo, sobretudo, Benveniste. E o faz, por exemplo, em um de seus ensaios, segundo busquei mostrar, deslocando categorias da/na língua em direção à situação do escritor com relação à escritura, o que gera contornos prospectivos para sua noção de escritura. Se a literatura é ciência da fala humana, como define o autor, ela só pode se constituir sobre a exploração da linguagem, "sem a qual ela não existiria" (BARTHES, 2012b, p. 25).

Este é apenas um pequeno exemplo que penso ressoar na "semiologia literária" que Barthes produz como ponto de chegada em Aula, texto que profere ao assumir a cadeira de mesmo nome no Collège de France: essa "semiologia literária" não se desvincula de uma teoria da escritura, já que, para Barthes, a literatura é uma prática, "a prática de escrever", o que o leva a assumir: "Posso dizer, indiferentemente: literatura, escritura ou texto" (BARTHES, 2013, p. 17).

Mas esses são desdobramentos que extrapolam o propósito do presente estudo, que consistiu, pontualmente, em mostrar alguns efeitos da reflexão benvenistiana sobre as proposições barthesianas, tal como eu os percebi em Escrever, verbo intransitivo?.

Destaco, assim, que o texto que ora escrevo consiste na reconstituição de uma leitura, da minha leitura: "ao ler, nós também imprimimos certa postura ao texto, e é por isso que ele é vivo; mas essa postura, que é nossa invenção, só é possível porque há entre os elementos do texto uma relação regulada, uma proporção: tentei analisar essa proporção" (BARTHES, 2012d, p. 29, grifo do autor), no caso deste trabalho, a proporção relativa aos efeitos de Benveniste em Barthes. E para que a minha leitura se tornasse, por sua vez, "objeto de uma nova leitura, tive evidentemente de sistematizar todos esses momentos em que a gente "levanta a cabeça'” (BARTHES, 2012d, p. 26). Fica, agora, o convite à interlocução.

\section{Referências}

BARTHES, Roland. Escritores e escreventes (1960). In: BARTHES, Roland. Crítica e verdade. São Paulo: Perspectiva, 1970. p. 31-39.

BARTHES, Roland. O grau zero da escrita: seguido de novos ensaios críticos. 2. ed. São Paulo: Martins Fontes, 2004.

BARTHES, Roland. Por que gosto de Benveniste. In: BARTHES, Roland. O rumor da língua. 3. ed. São Paulo: WMF Martins Fontes, 2012a. p. 207-213. https://doi.org/10.2307/j.ctt5vjk9q.13

BARTHES, Roland. Escrever, verbo intransitivo? (1966). In: BARTHES, Roland. O rumor da língua. 3. ed. São Paulo: WMF Martins Fontes, 2012b. p. 13-25. 
BARTHES, Roland. A morte do autor (1968). In: BARTHES, Roland. O rumor da língua. 3. ed. São Paulo: WMF Martins Fontes, 2012c. p. 57-64.

BARTHES, Roland. Escrever a leitura (1970). In: BARTHES, Roland. O rumor da língua. 3. ed. São Paulo: WMF Martins Fontes, 2012d. p. 26-29.

BARTHES, Roland. Aula: aula inaugural da carreira de Semiologia Literária do Colégio de França, pronunciada dia 7 de janeiro de 1977. Trad. e posfácio de Leyla Perrone-Moisés. São Paulo: Cultrix, 2013.

BELLOCCHIO, Carolina Molinar. Uma visão sutil do mundo: escritura, enunciação e variação em Roland Barthes. Tese (Doutorado em Letras). Orientadora: Profa. Dra. Claudia Amigo Pino. 2017. 308f. Programa de Pós-Graduação em Estudos Linguísticos, Literários e Tradutológicos em Francês, do Departamento de Letras Modernas da Faculdade de Filosofia, Letras e Ciências Humanas, Universidade de São Paulo (USP), São Paulo (SP), 2017.

BENVENISTE, Émile. Ativo e médio no verbo (1950). In: BENVENISTE, Émile. Problemas de linguística geral I. 5.ed. Campinas, SP: Pontes Editores, 2005a. p. 183-191.

BENVENISTE, Émile. A natureza dos pronomes (1956). In: BENVENISTE, Émile. Problemas de linguística geral I. 5.ed. Campinas, SP: Pontes Editores, 2005b. p. 277-283.

BENVENISTE, Émile. Da subjetividade na linguagem (1958). In: BENVENISTE, Émile. Problemas de linguística geral I. 5.ed. Campinas, SP: Pontes Editores, 2005c. p. 284-293.

BENVENISTE, Émile. As relações de tempo no verbo francês (1959). In: BENVENISTE, Émile. Problemas de linguística geral I. 5.ed. Campinas, SP: Pontes Editores, 2005d. p. 260-276.

BENVENISTE, Émile. Os níveis da análise linguística (1962). In: BENVENISTE, Émile. Problemas de linguística geral I. 5.ed. Campinas, SP: Pontes Editores, 2005e. p. 127-140.

BENVENISTE, Émile. Saussure após meio século (1963). In: BENVENISTE, Émile. Problemas de linguística geral I. 5.ed. Campinas, SP: Pontes Editores, 2005f. p. 34-49.

BENVENISTE, Émile. Vista d'olhos sobre o desenvolvimento da linguística. In: BENVENISTE, Émile. Problemas de linguística geral I. 5.ed. Campinas, SP: Pontes Editores, 2005g. p. 19-33.

BENVENISTE, Émile. Problemas de linguística geral II. 2.ed. Campinas, SP: Pontes Editores, 2006.

FLORES, Valdir do Nascimento. Introdução à teoria enunciativa de Benveniste. São Paulo: Parábola, 2013.

ROSÁRIO, Heloísa Monteiro. Um périplo benvenistiano: o semiólogo e a semiologia da língua. Tese (Doutorado em Estudos da Linguagem). Orientador: Prof. Dr. Valdir do Nascimento Flores. 2018. 173 f. Programa de Pós-Graduação em Letras, Universidade Federal do Rio Grande do Sul (UFRGS), Porto Alegre (RS), 2018.

PERRONE-MOISÉS, Leyla. Posfácio: Lição de Casa. In: BARTHES, Roland. Aula: Aula Inaugural da Cadeira de Semiologia Literária do Colégio de França. São Paulo: Cultrix, 2013.

PERRONE-MOISÉS, Leyla. Prefácio. In: BARTHES, Roland. O rumor da língua. 3. ed. São Paulo: WMF Martins Fontes, 2012. p. 9-20. 
TEIXEIRA, Marlene; MESSA, Rosângela M. Émile Benveniste: uma semântica do homem que fala. Estudos da língua(gem). Vitória da Conquista, v. 13, n. 1, p. 97-116, 2015. https://doi.org/10.22481/el.v13i1.1281

Recebido em: 19/11/2019.

Aceito em: 09/03/2020. 